\title{
AN ANP-BASED SIMULATION OF VULNERABILITY OF TWO- WAY COUPLED SOCIO-ECOLOGICAL SYSTEMS
}

\begin{abstract}
A spatially explicit, integrated modeling approach in presented here that simulates the twoway coupling of complex socio-ecological systems. A key component of our method is the use of the Analytic Network Process (ANP), a MCDA technique based on the super-matrix approach, to operationalize the dynamic feedback between mental models and the situation at the geographic automata; the ANP generates the priority weights that determine the decisions dynamically. The approach is illustrated as it is being implemented in MEGADAPT (MEGAcity-ADAPTation) - a model that addresses the challenging task of eliciting the vulnerability of Mexico City to underlying socio-hydrological and climatic risks.
\end{abstract}

Keywords: GIS-MCDA, Vulnerability, Self-organizing systems, Geographic automata,

\section{Introduction}

We present here the implementation of the Analytic Network Process (ANP, Saaty 2001) in an integrated modeling approach to simulate the two-way coupling of complex socioecological systems, as it is being implemented in the MEGADAPT (MEGAcityADAPTation) a spatial decision support system to depicts and helps explain sociohydrological and climatic risks in Mexico City. MEGADAPT is a dynamic, spatially explicit and integrated modeling approach to simulate the two-way coupling of complex socio-ecological systems from the perspective of self-organized systems. MEGADAPT simulates how the decisions by the water authority to address vulnerability at the local scale modify the internal structure and function of the whole socio-ecological system at the Mexico City scale. Results depict the behavior of socio-ecological systems switching from one-way coupling and single-loop learning to two-way coupling and double -loop learning as an outcome of endogenous drivers of the decision-making process. Our focus is on showing how the two-way coupling of socio-ecological systems is operationalized geographic information systems-multicriteria decision analysis (GIS-MCDA), multiobjective optimization, and geosimulation (Malczewski and Rinner 2015).

\section{Literature Review}

While vulnerability and adaptability to climate change has been studied from a coupled socio-ecological systems perspective, there has been less emphasis on how actors learn in the process of adaptation, and the effect of mental models held by powerful agents on patterns of vulnerability in a landscape (Eakin et al. 2017). Learning thus is a central component of adaptive capacity: agents must have the capacity not only to reflect on and improve the outcomes of their decisions, but also to modify the values and priorities that are determining what decisions they take and why - in other words, double-loop learning (Argyris 1976). In MEGADAPT, the two-way coupling of the socio-ecological system was achieved by means of the ANP, a technique that has been increasingly used in GIS-MCDA 
ISAHP Article: A Style Guide for Paper Proposals To Be Submitted to the International Symposium on the Analytic Hierarchy Process 2018, Hong Kong, HK.

given its capacity for incorporating a variety of interactions, dependencies, and feedbacks amongst decision criteria (e.g., Bojórquez-Tapia et al. 2011; Tran et al. 2004).

\section{Objectives}

Our research specifically deals with one challenging problem in vulnerability research. This concerns the often poor representation of decision-making and decision-makers as endogenous drivers of vulnerability patterns, processes and outcomes. We simulate the vulnerability of Mexico City to socio-hydrological risk through MEGADAPT. In this regard, we demonstrate how the super-matrix approach of the ANP is essential for the dynamic simulations of the effect on vulnerability of both single-loop and double loop learning.

\section{Research Design/Methodology}

We convened an expert consultation workshop in October 2015, to which group of experts and water managers from the Mexico City's water management agency, SACMEX (Sistema de Aguas de la Ciudad de México) were invited. All the experts were professionally involved in managing the city's water and sewage systems. This knowledge and experience was combined with the available official data at SACMEX. During the workshop, we facilitated the experts' definition of a network structure to represent their conceptualization of socio-hydrological vulnerability in the city using the ANP, which was implemented by means of Super Decisions v.1.6.0. The simulation of both one-way and two-way coupling of socio-ecological systems is operationalized through geographic information systems-multicriteria decision analysis (GIS-MCDA), multi-objective optimization, and geosimulation that consists in merging cellular automata (CA) and agent based modeling (ABM) into "geographic automata".

\section{Data/Model Analysis}

The experts defined the subnetwork of sewerage as consisting of five clusters (Figure 2): Three were composed by elements representing environmental, socio-institutional, infrastructural drivers of vulnerability, respectively, one by elements representing sociohydrological risks, and the final cluster by elements representing actions to address risk.

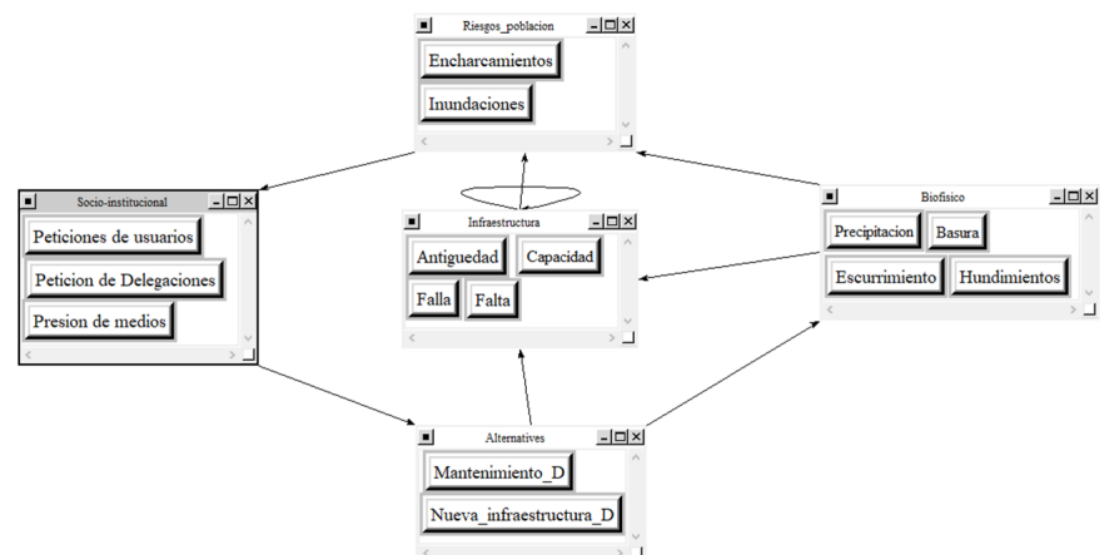

The

model derived from the consultation with experts from the water authority produced the weighted super-matrix for subsystem sewerage, $\mathbf{W}$, which comprised 25 block matrices. 
ISAHP Article: A Style Guide for Paper Proposals To Be Submitted to the International Symposium on the Analytic Hierarchy Process 2018, Hong Kong, HK.

For the sake of illustration, let's assume that statistical data is available that demonstrates that runoff gives rise to $75 \%$ of the cases of ponding and $25 \%$ of the cases of flooding, whereas rainfall gives rise to $17 \%$ of the cases of ponding and $83 \%$ of the cases of flooding. These data are incorporated in block matrix $\mathbf{W}_{\mathbf{5 2}}$ (shaded in gray) at the beginning of the simulation as follows:

\begin{tabular}{|c|c|c|c|c|c|c|c|c|c|c|c|c|c|c|c|c|}
\hline \multirow[t]{2}{*}{ Cluster } & \multirow[t]{2}{*}{ Element } & \multicolumn{2}{|c|}{ A } & \multicolumn{4}{|c|}{$\mathrm{E}$} & \multicolumn{4}{|c|}{1} & \multicolumn{3}{|c|}{$\mathrm{s}$} & \multicolumn{2}{|c|}{$\mathrm{R}$} \\
\hline & & Ma & $\mathrm{Bu}$ & $\mathrm{Ga}$ & $\mathrm{Ru}$ & Su & $\mathrm{Rf}$ & Ol & $\mathrm{Ca}$ & $\mathrm{Fa}$ & De & $\mathrm{Mu}$ & $\mathrm{Ci}$ & $\mathrm{Me}$ & Po & $\mathrm{FI}$ \\
\hline \multirow{3}{*}{ Actions (A) } & Mainta & 0.00 & 0.00 & 0.00 & 0.00 & 0.00 & 0.00 & 0.00 & 0.00 & 0.00 & 0.00 & 0.17 & 0.25 & 0.75 & 0.00 & 0.00 \\
\hline & Buil & 00 & 0.00 & 0.00 & 0.00 & 0.00 & 0.00 & 0.00 & 0.00 & 0.00 & 0.00 & 0.83 & 0.75 & 0.25 & 0.00 & 0.00 \\
\hline & $\mathrm{Ga}$ & & 0.00 & 0.00 & 0.00 & 0.00 & 0.00 & 0.00 & 0.00 & 0.00 & 0.00 & 0.00 & 0.00 & 0.00 & 0.00 & 0.00 \\
\hline \multirow{3}{*}{ Environment $(E)$} & Run & 50 & 0.25 & 0.00 & 0.00 & 0.00 & 0.00 & 0.00 & 0.00 & 0.00 & 0.00 & 0.00 & 0.00 & 0.00 & 0.00 & 0.00 \\
\hline & Sut & 04 & 0.00 & 0.00 & 0.00 & 0.00 & 0.00 & 0.00 & 0.00 & 0.00 & 0.00 & 0.00 & 0.00 & 0.00 & 0.00 & 0.0 \\
\hline & $\mathrm{Re}$ & 34 & 0.75 & 0.00 & 0.00 & 0.00 & 0.00 & 0.00 & 0.00 & 0.00 & 0.00 & 0.00 & 0.00 & 0.00 & 0.00 & 0.0 \\
\hline \multirow{4}{*}{ Infr } & & & 0.00 & 0.00 & 0.00 & 0.00 & 0.00 & 0.00 & 0.00 & 0.00 & 0.00 & 0.00 & 0.00 & 0.00 & 0.00 & 0 \\
\hline & & & 0.17 & 0.90 & 0.00 & 0.10 & 0.00 & 0.33 & 0.00 & 0.00 & 0.00 & 0.00 & 0.00 & 0.00 & 0.00 & 0.0 \\
\hline & & 25 & 0.00 & 0.10 & 0.00 & 0.90 & 0.00 & 0.67 & 0.00 & 0.00 & 0.00 & 0.00 & 0.00 & 0.00 & 0.00 & 0.0 \\
\hline & Defi & 0.00 & 0.83 & 0.00 & 0.00 & 0.00 & 0.00 & 0.00 & 0.00 & 0.00 & 0.00 & 0.00 & 0.00 & 0.00 & 0.00 & 0.0 \\
\hline \multirow{3}{*}{ Socio-institutional (S) } & & & 0.00 & 0.00 & 0.00 & 0.00 & 0.00 & 0.00 & 0.00 & 0.00 & 0.00 & 0.00 & 0.00 & 0.00 & 0.00 & 0.2 \\
\hline & & b & 0.00 & 0.00 & 0.00 & 0.00 & 0.00 & 0.00 & 0.00 & 0.00 & 0.00 & 0.00 & 0.00 & 0.00 & 0.67 & 0.1 \\
\hline & Media $(\mathrm{Me})$ & 0.00 & 0.00 & 0.00 & 0.00 & 0.00 & 0.00 & 0.00 & 0.00 & 0.00 & 0.00 & 0.00 & 0.00 & 0.00 & 0.33 & 0.64 \\
\hline \multirow{2}{*}{$\begin{array}{l}\text { Socio-hydrological } \\
\text { risk (R) }\end{array}$} & & 0 & 0.00 & 0.00 & 0.75 & 0.90 & 0.17 & 0.00 & 0.75 & 0.75 & 0.25 & 0.00 & 0.00 & 0.00 & 0.00 & 0.0 \\
\hline & Floo & 0.00 & 0.00 & 0.00 & 0.25 & 0.10 & 0.83 & 0.00 & 0.25 & 0.25 & 0.75 & 0.00 & 0.00 & 0.00 & 0.00 & 0.0 \\
\hline
\end{tabular}

Given this super-matrix, the geographic automata allocated action building new infrastructure to a higher number of alternatives of the decision space, and action maintaining existing infrastructure to the remaining ones.

After year 20, the average values of both socio-hydrological risk and oldness were large enough as to produce a switch of the preferences for the two actions (Figure 4, Table 2). The output of Stage 1 showed that the changes in the socio-ecological system were sufficiently large to modify the statistical relationships represented in block matrix W_52. Now, runoff gave rise to $10 \%$ of the cases of ponding and $90 \%$ of the cases of flooding, whereas rainfall gave rise to $50 \%$ of the cases of both ponding and flooding. These results modified block matrix $\mathbf{W}_{\mathbf{5 2}}$ accordingly. Given these new conditions, results of the limit super-matrix showed that the weights for elements flooding, media reporting, municipal petitions, oldness, failure, and runoff increased, whereas the weights for elements ponding, citizen complaint, deficiency, and rainfall decreased. As an outcome, the weight for maintaining existing infrastructure became slightly higher than that for building new infrastructure.

\begin{tabular}{|c|c|c|c|c|c|}
\hline \multirow{3}{*}{ Cluster } & \multirow{3}{*}{ Element } & \multicolumn{4}{|c|}{ Importance weight } \\
\hline & & \multicolumn{2}{|c|}{$\begin{array}{c}\text { One-way coupling } \\
\text { (single loop) }\end{array}$} & \multicolumn{2}{|c|}{$\begin{array}{l}\text { Two-way coupling } \\
\text { (double loop) }\end{array}$} \\
\hline & & Limit & Normalized & Limit & Normalized \\
\hline \multirow{2}{*}{ Actions (A) } & Maintainning (Ma) & 0.115 & 0.483 & 0.120 & 0.505 \\
\hline & Building $(\mathrm{Bu})$ & 0.123 & 0.517 & 0.118 & 0.495 \\
\hline \multirow{4}{*}{ Environment (E) } & Garbage (Ga) & 0.007 & 0.009 & 0.007 & 0.009 \\
\hline & Runoff $(\mathrm{Ru})$ & 0.044 & 0.058 & 0.045 & 0.059 \\
\hline & Subsidence (Su) & 0.002 & 0.003 & 0.002 & 0.003 \\
\hline & Rainfall (Rf) & 0.066 & 0.086 & 0.065 & 0.084 \\
\hline \multirow{4}{*}{ Infrastructure (I) } & Oldness (OI) & 0.043 & 0.056 & 0.045 & 0.059 \\
\hline & Capacity (Ca) & 0.031 & 0.040 & 0.031 & 0.040 \\
\hline & Failure (Fa) & 0.045 & 0.059 & 0.047 & 0.061 \\
\hline & Deficiency (De) & 0.051 & 0.067 & 0.049 & 0.064 \\
\hline \multirow{3}{*}{ Socio-institutional (S) } & Municipal (Mu) & 0.032 & 0.042 & 0.042 & 0.055 \\
\hline & Citizens (Ci) & 0.090 & 0.117 & 0.067 & 0.088 \\
\hline & Media (Me) & 0.117 & 0.152 & 0.129 & 0.168 \\
\hline \multirow{2}{*}{ Socio-hydrological risk (R) } & Ponding (Po) & 0.115 & 0.150 & 0.075 & 0.098 \\
\hline & Flooding (FI) & 0.124 & 0.161 & 0.163 & 0.212 \\
\hline
\end{tabular}


ISAHP Article: A Style Guide for Paper Proposals To Be Submitted to the International Symposium on the Analytic Hierarchy Process 2018, Hong Kong, HK.

\section{Limitations}

An exploratory modeling rationale is used in MEGADAPT to tackle the insufficient knowledge and unresolvable uncertainties concerning Mexico City's vulnerability. Hence, MEGADAPT entails the use of computational experiments to allow decision-makers and stakeholders be interactively involved in reasoning about Mexico City's vulnerability patterns. Results show the spatial distribution, and temporal dynamics of risk according to the expectations of the different stakeholders, generating in this way new insights about the role of soft infrastructure in shaping the emergence, evolution, and function of sociohydrological risk in Mexico City. MEGADAPT's heuristic modeling approach thus synthesizes the conflicting decision-making processes concerning both socio-political and engineering infrastructures.

\section{Conclusions}

Results show the spatial distribution, and temporal dynamics of risk according to the expectations of the different stakeholders, generating in this way new insights about the role of soft infrastructure in shaping the emergence, evolution, and function of sociohydrological risk in Mexico City. MEGADAPT's heuristic modeling approach thus synthesizes the conflicting decision-making processes concerning both socio-political and engineering infrastructures the super-matrix approach of the ANP proved to be essential for the dynamic simulations of the effect on vulnerability of both single-loop and double loop learning.

\section{Key References}

Argyris, Chris. 1976. "Single-Loop and Double-Loop Models in Research on Decision Making." Administrative Science Quarterly 21 (3): 363:

Bojórquez-Tapia, Luis A. et al. 2011. "Regional Environmental Assessment for Multiagency Policy Making: Implementing an Environmental Ontology through GISMCDA." Environment and Planning B: Planning and Design 38 (3): 539-63

Malczewski, J., and Rinner, C. 2016. Multicriteria decision analysis in geographic information science. Springer

Saaty, T. L. (2001). Creative thinking, problem solving and decision making. Rws Publications. 